\title{
Saliva versus Plasma Bioequivalence of Valsartan| Hydrochlorothiazide in Humans: Validation of Classes II and IV Drugs of the Salivary Excretion Classification System
}

\author{
Authors \\ Nasir Idkaidek, Haneen Agha, Tawfiq Arafat
}

Affiliation

University of Petra, College of Pharmacy, Amman, Jordan

Key words

salivary excretion classification system, valsartan/hydrochlorothiazide, bioequivalence, pharmacokinetics, Pk-Sim/MoBi

received 14.05 .2017

accepted 26.07.2017

\author{
Bibliography \\ DOI https://doi.org/10.1055/s-0043-117775 \\ Published online: 28.8 .2017 \\ Drug Res 2018; 68: 54-59 \\ (c) Georg Thieme Verlag KG Stuttgart · New York \\ ISSN 2194-9379
}

Correspondence
Nasir Idkaidek
University of Petra
College of Pharmacy
Airport Street
PO Box 961343
Amman
Jordan
Tel.: +962/6/5799 555, Fax: +962/6/5715 570
nidkaidek@uop.edu.jo

\begin{abstract}
Aim The aim of this study is to investigate the robustness of using non-invasive saliva instead of plasma for bioequivalence of valsartan and hydrochlorothiazide (HCT) in humans based on Salivary Excretion Classification System (SECS).

Methods Plasma and resting saliva samples were collected over $24 \mathrm{~h}$ after oral administration of single dose $160 \mathrm{mg}$ valsartan and $12.5 \mathrm{mg} \mathrm{HCT}$ to 12 healthy male volunteers after $10 \mathrm{~h}$ overnight fasting. Plasma and saliva concentrations were determined by validated liquid chromatography-mass spectrometry. WinNonlin program V5.2 was used to determine pharmacokinetic parameters and bioequivalence metrics. Moreover, optimized effective intestinal permeability was estimated using PK-Sim/Mobi program V5.6.

Results and Discussion Valsartan is SECS class IV drug due of low permeability and high protein binding and hence didn't appear in saliva. However, HCT is SECS class II drug due to low permeability and low protein binding. No significant differences were observed in the pharmacokinetic parameters in both plasma matrix and saliva matrix $(\mathrm{P}>0.05)$. The $90 \%$ confidence intervals did not pass in all parameters due to the high intra-subject variability and small sample size used in this study. Saliva to plasma ratios of HCT were low, yet with high correlation coefficient of $0.96-0.98$. So saliva can be used as alternative to plasma sample in pharmacokinetic studies and in bioequivalence when adequate sample size is used.
\end{abstract}

\section{Introduction}

The protein binding of drug and membrane permeability were previously investigated for several drugs as major factors for salivary excretion where a Salivary Excretion Classification System was proposed (SECS) [1]. High intestinal permeability corresponds to fraction absorption $(\mathrm{Fa})>0.9$, while high protein binding corresponds to low fraction unbound ( $\mathrm{fu}$ ) of $<0.1$. Based on SECS, class I drugs of high intestinal permeability and low protein binding, such as paracetamol, are subject to salivary excretion. Class II drugs of low permeability and low protein binding, such as metformin, are subject to salivary excretion since low permeability is counterbalanced by low protein binding. Class III drugs of high intestinal permeability and high protein binding, such as rusovastatin, are subject to salivary excretion since high protein binding is counterbalanced by high permeability. Class IV drugs of low intestinal permeability and high protein binding, such as montelukast, are not subject to salivary excretion [1].

Salivary excretion of some drugs has been reported previously as a good indicator for drug bioavailability, therapeutic drug monitoringdrug abuse and pharmacokinetics. Saliva sampling method is a simple, non-invasive, and cheap with less stress or pain and no risk of infection compared with plasma sampling method [2-11].

Valsartan is a non-peptide angiotensin II type $1\left(\mathrm{AT}_{1}\right)$ receptor blockers [12].It's rapidly absorbed after oral administration and eliminated mainly as unchanged drug via biliary excretion [13, 14]. In case of renal dysfunction, there is no effect on the pharmacokinetics of valsartan. Also the pharmacokineticsis not affected by age [15]. Valsartan is used for the treatment of hypertension either alone or in combination therapy and its effect in reducing blood pressure persists throughout the 24-h after dosing. It is also effective for heart failure and post myocardial infarction patients [16]. Hydrochlorothi- 
azide, it's a thiazide diuretic and its well absorbed after oral administration with a bioavailability ranging from 60-80\% [17]. Hydrochlorothiazide is widely used for the treatment of hypertension either alone or in combination with other antihypertensive drugs. Hydrochlorothiazide also usedfor the treatment of edema associated with heart failure, liver cirrhosis and nephrotic syndrome [18]. The combination of valsartan and hydrochlorothiazide provides further blood pressure lowering than the individual components [16].

\section{Objectives}

The aim of this study is to investigate the robustness of using noninvasive saliva sampling method instead of plasma sampling method for this combination (valsartan and hydrochlorothiazide) in bioequivalence and in pharmacokinetic studies for drugs that are excreted in saliva according to SECS.

\section{Methods}

\section{Study Design}

Saliva pharmacokinetics were compared with plasma pharmacokinetics in 12 healthy male subjects under a fasted state after signing the informed consent and passing the laboratory test to participate in a two-way, cross-over design study with wash-out period of 7 days. Medical history, vital signs, physical examination showed no evidence of clinically significant deviation from normal medical condition as evaluated by the clinical investigator. This study was conducted at Red Crescent Hospital as per the International Conference on Harmonization (ICH), Good Clinical Practice (GCP) and Helsinki declaration guidelines, after Institutional Review Board (IRB) of Jordan Center for Pharmaceutical Research (JCPR) and Jordan Food and Drug Administration (JFDA) approvals.

A single oral dose of valsartan/hydrochlorothiazide $160 / 12.5 \mathrm{mg}$ of either test drugCo-Diotens ${ }^{\circledR}$ tablets, batch no. 160159 or reference drug Co-Diovan ${ }^{\circledR}$ tablets, batch no. T9169 with $240 \mathrm{ml}$ of water was given after $10 \mathrm{~h}$ overnight fasting without dietary restriction.Plasma samples and resting (unstimulated) saliva samples were collected at the following times: $0,0.33,0.66,1,1.33,1.66$, $2,2.5,3,3.5,4,5,6,8,10,12$ and 24 post drug administrations during each study period. Blood samples were collected in a heparin tube and separated by centrifuge apparatus. Plasma samples and saliva samples were kept frozen at $-20^{\circ} \mathrm{C}$ until analysis.

\section{Assay Methodology}

Plasma and saliva samples that kept frozen were assayed by a validated liquid chromatography-mass spectrometry (LC-MS) assay method. The chromatographic conditionsused were, column type: ACE $5 \mathrm{C}_{8}(50 \times 2.1 \mathrm{~mm}), 5 \mu \mathrm{m}$, the, mobile phase was, A: $(0.04 \%$ Ammonia (10\%) \& $0.04 \%$ Formic acid) and B: $85.0 \%$ methanol and the total run time was $0.80 \mathrm{~min}$. the extraction method was as the following:

- Pipette $300 \mu \mathrm{L}$ of blank and spiked plasma samples into the appropriately labeled tubes.

- Add $50 \mu \mathrm{L}$ of internal standard $\left(0.50 \mu \mathrm{g} / \mathrm{mL}\right.$ of HCT- ${ }^{13} \mathrm{CD}_{2}$ and $2.0 \mu \mathrm{g} / \mathrm{mL}$ of Valsartan- $\left.D_{3}\right)$, and vortex for $15 \mathrm{~s}$.

- Add $30 \mu \mathrm{L}$ of extraction buffer ( $5 \%$ Formic acid), and vortex for $15 \mathrm{~s}$.
- Add $6 \mathrm{~mL}$ of extraction solvent (ethyl acetate) and vortex for 5.0 min.

- Centrifuge the samples for 6 min at 4400 rpm.

- Freeze the samplesfor about 30 min, and then decant the organic layer in a clean evaporating glass tube.

- Evaporate the extraction solvent by compressed air in water bath at $40{ }^{\circ} \mathrm{C}$, then reconstitute with $250 \mu \mathrm{L}$ of reconstitution solution (water: methanol) (35:65\%; v/v) and vortex for $1 \mathrm{~min}$. ( this step should be conducted in the fume hood)

- Transfer the samples into a flat bottom insert's vials, and inject to instrument.

\section{Data analysis}

\section{Pharmacokinetic parameters}

Individual pharmacokinetic parameters for drug concentration of both analytes (valsartan and hydrochlorothiazide) in plasma and saliva were calculated by non-compartmental analysis (NCA), using WinNonlinV5.2. Pharmacokinetic parameters were area under the concentration curves to last collection time $\left(A \cup C_{0 \rightarrow t}\right)$, area under the concentration curves to infinity $\left(A \cup C_{0 \rightarrow \infty}\right)$, maximum measured concentration $\left(C_{\max }\right)$, time to maximum concentration $\left(T_{\max }\right)$, elimination rate constant $\left(\mathrm{K}_{\mathrm{el}}\right)$ and half-life $\left(\mathrm{t}_{0 \cdot 5}\right)$. Statistical t-tests were done for pharmacokinetic parameters $\left(\mathrm{AUC}_{0 \rightarrow 24}, \mathrm{AUC}_{0 \rightarrow \infty}, \mathrm{C}_{\mathrm{max}}, \mathrm{K}_{\mathrm{el}}\right.$ and $\left.\mathrm{t}_{0 \cdot 5}\right)$, while Wilcoxon test was done for $\mathrm{T}_{\max }$.

\section{Bioequivalence analysis}

Analysis of variance (ANOVA) was done according to EMA guideline on bioequivalence. It includes sequence and subject (sequence) as random effects, treatment and period as fixed effects without interaction terms. Level of significance used was 0.05 for all effects. Also, $90 \%$ confidence intervals and intra-subject variability estimates for primary pharmacokinetic parameters $\left(A \cup C_{0 \rightarrow \mathrm{t}}, A \cup C_{0 \rightarrow \infty}\right.$ and $\left.C_{\text {max }}\right)$ for testversusreference after logarithmic transformation were calculated by WinNonlinprogram V5.2.

\section{Dimensional and correlation analysis}

Saliva versus plasma concentrations up to median $\mathrm{T}_{\max }$ were correlated by linear regression using Microsoft Excel program. Dimensional analysis was done on an individual basis for each volunteer.

Dimensional analysis offers the advantage of more clear comparisons since ratios are unit less. The following dimensionless ratios were calculated:

$$
\begin{aligned}
& \mathrm{AUC}^{*} \text { = saliva } A \cup C_{0 \rightarrow \mathrm{t}} / \text { plasma } \mathrm{AUC}_{0 \rightarrow \mathrm{t}} \\
& \mathrm{T}_{\max }{ }^{*}=\text { saliva } \mathrm{T}_{\max } / \text { plasma } \mathrm{T}_{\max } \\
& \mathrm{C}_{\max }{ }^{*}=\text { saliva } C_{\max } / \text { plasma } C_{\max } \\
& \mathrm{C}^{*}=\text { saliva concentration/plasma concentration }=C_{\mathrm{s}} / C_{\mathrm{p}}
\end{aligned}
$$

However, $C^{*}$ is calculated by using $C_{s} / C_{p}$ at each sampling time for 12 subjects.

\section{Optimized effective intestinal permeability}

Effective intestinal permeability $\left(P_{\text {eff }}\right)$ values were estimated by PK$\mathrm{Sim} /$ Mobi program V5.6. This was done by searching for the best 
parameter values that produce plasma concentration that matches the actual plasma concentration at the same time.

Fraction absorption ( $\mathrm{Fa}$ ) was calculated according to equations below:

$$
\begin{aligned}
& \mathrm{Fa}=1-\mathrm{e}^{-2 \mathrm{An}} \\
& \mathrm{An}=\mathrm{P}_{\text {eff }} \mathrm{t}_{\text {res }} / \mathrm{R}
\end{aligned}
$$

Where $A n$ is the absorption number, $R$ and $t_{\text {res }}$ are radius, set at $1.75 \mathrm{~cm}$, and mean residence time, set at $3 \mathrm{~h}$, in the human small intestine respectively.

\section{Results and Discussion}

Valsartan falls into SECS class IV with low permeability $(\mathrm{Fa}=0.46)$ and high protein binding (Fu=0.05). As a result valsartan didn't appear in saliva. Mean plasma valsartan concentrations of test and reference formulations are shown in $\mathbf{F i g}$. 1. The pharmacokinetic parameters of test and reference formulationswere calculated and showed no significant differences since $(P>0.05)$, as shown in - Table 1.

Bioequivalence metrics and intra-subject variabilityvalues for primary pharmacokinetic parameters, $\mathrm{AUC}_{0 \rightarrow 24}, \mathrm{AUC}_{0 \rightarrow \infty}$ and $\mathrm{C}_{\max }$ in plasma were calculated. The $90 \%$ confidence intervalsdidn't fall within the acceptance range of $80-125 \%$ because the small sample size used and this is expected due to the high intra-subject variability observed in this study as shown in $>$ Table 2 . In addition,

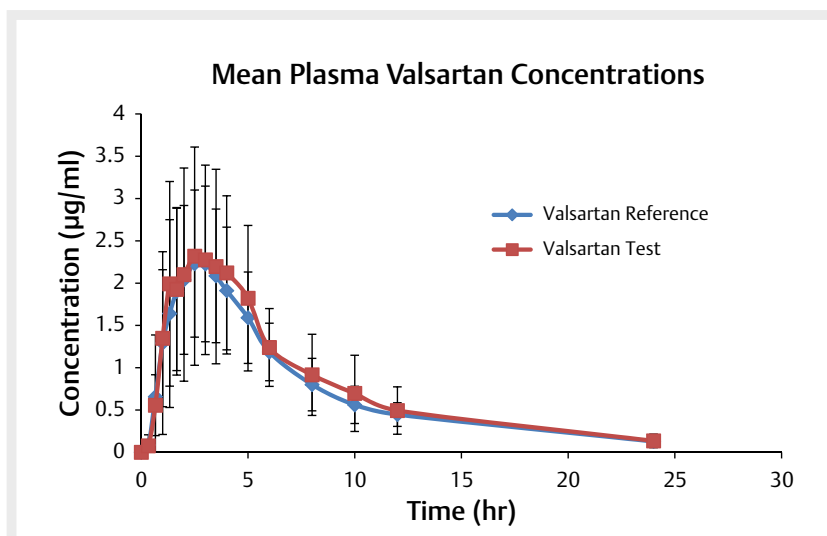

- Fig. 1 Mean plasma valsartan concentrations-time profiles.

- Table 1 Plasma pharmacokinetic parameters of valsartan test and refer-

\begin{tabular}{|c|c|c|c|}
\hline Parameter & Test & Reference & $P$ value \\
\hline$A U C_{0 \rightarrow \mathrm{t}}(\mu \mathrm{g} / \mathrm{ml} \mathrm{h})$ & 19.01 & 17.41 & 0.723 \\
\hline $\mathrm{AUC}_{0 \rightarrow \infty}(\mu \mathrm{g} / \mathrm{ml} \mathrm{h})$ & 20.32 & 18.63 & 0.689 \\
\hline$C_{\max }(\mu \mathrm{g} / \mathrm{ml})$ & 2.73 & 2.55 & 0.702 \\
\hline$T_{\max }(h)$ & 2.78 & 3.21 & $0.386 *$ \\
\hline$K_{\text {el }}(h-1)$ & 0.12 & 0.12 & 0.572 \\
\hline$t_{0.5}(h)$ & 6.15 & 6.15 & 0.748 \\
\hline
\end{tabular}
ence formulations.

ANOVAp values showed no significant differences between test and reference in all sources of variability as shown in > Table 3

Hydrochlorothiazide falls into SECS class II with low permeability $(\mathrm{Fa}=0.01)$ and low protein binding $(\mathrm{Fu}=0.33)$ which is consistent with the previous finding [1]. Mean plasma and saliva hydrochlorothiazide concentrations of test and reference formulationsare shown in - Fig. 2. The profiles showed good salivary excretionwith correlation coefficient of 0.98 and 0.96 between plasma and saliva up to median $\mathrm{T}_{\max }$ for test and reference respectively as shown in $\triangleright$ Fig. 3 . The pharmacokinetic parameters of test and reference formulations in both plasma and saliva were calculated and the statistical analysis showed no significant differencesbetween test and reference in both plasma matrix and saliva matrix since $(\mathrm{P}>0.05)$, as shown in $>$ Tables 4, 5 respectively. Bioequivalence metrics and intra-subject variability values for primary pharmacokinetic parameters $\mathrm{AUC}_{0 \rightarrow 24}, \mathrm{AUC}_{0 \rightarrow \infty}$ and $\mathrm{C}_{\max }$ in both plasma and saliva were calculated. The $90 \%$ confidence intervals

- Table 2 Bioequivalence metrics: point estimate (90\% lower limit-90\% upper limit), intra-subject variability \% for valsartan after log transformation.

\begin{tabular}{|l|c|}
\hline Parameter & Plasma \\
\hline AUC $_{\mathbf{0} \rightarrow \mathbf{t}}$ & $105.5(81.2-136.9), 36.4$ \\
\hline AUC $_{\mathbf{0} \rightarrow \infty}$ & $106.1(82.4-136.6), 35.2$ \\
\hline $\mathbf{C}_{\max }$ & $108.3(75.8-154.8), 51.2$ \\
\hline
\end{tabular}

Table 3 ANOVA $P$ values of $\left(\mathrm{AUC}_{0 \rightarrow \mathrm{t}}, \mathrm{AUC}_{0 \rightarrow \infty}, \mathrm{C}_{\max }\right)$ for valsartan in plasma*.

\begin{tabular}{|l|c|}
\hline Source & \multicolumn{1}{c|}{ Plasma } \\
\hline Sequence & $0.864,0.674,0.489$ \\
\hline Subject (Sequence) & $0.573,0.541,0.781$ \\
\hline Treatment & $0.719,0.682,0.694$ \\
\hline Period & $0.256,0.227,0.258$ \\
\hline $\begin{array}{l}* \text { ANOVA analysis of variance; } \mathrm{AUC}_{0 \rightarrow 24} \text { area under concentration } \\
\text { curves to last collection time; } \mathrm{AUC}_{0 \rightarrow \infty} \text { area under concentration } \\
\text { curves to infinity; } \mathrm{C}_{\text {max }} \text { maximum measured concentration. Level of } \\
\text { significance is } 0.05\end{array}$ \\
\hline
\end{tabular}

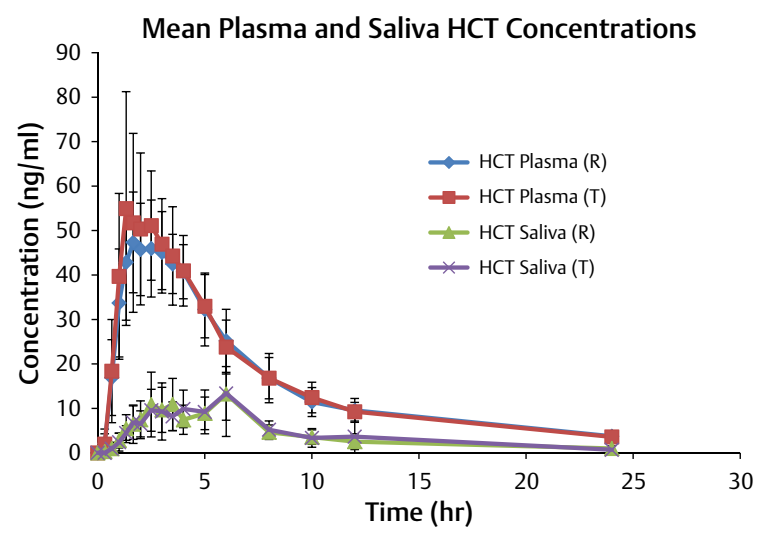

Fig. 2 Mean plasma and saliva hydrochlorothiazide concentrations-time profiles.

${ }^{*}$ : Wilcoxon test was done for $\mathrm{T}_{\max }$ 


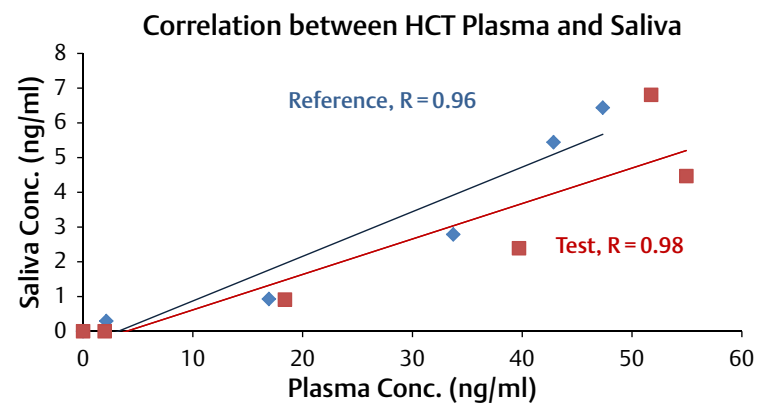

Fig. 3 Correlations of plasma and saliva hydrochlorothiazide mean concentrations.

- Table 4 Plasma pharmacokinetic parameters of hydrochlorothiazide test and reference formulations.

\begin{tabular}{|c|c|c|c|}
\hline Parameter & Test & $\begin{array}{l}\text { Refer- } \\
\text { ence }\end{array}$ & $P$ value \\
\hline $\mathrm{AUC}_{0 \rightarrow 24}(\mathrm{ng} / \mathrm{ml} \mathrm{h})$ & 392.19 & 380.05 & 0.544 \\
\hline$A U C_{0 \rightarrow \infty}(\mathrm{ng} / \mathrm{ml} \mathrm{h})$ & 432.41 & 421.38 & 0.640 \\
\hline$C_{\max }(\mathrm{ng} / \mathrm{ml})$ & 62.27 & 52.30 & 0.252 \\
\hline$T_{\max }(\mathrm{h})$ & 2.30 & 2.35 & $0.678^{*}$ \\
\hline$K_{e l}(h-1)$ & 0.09 & 0.09 & 0.988 \\
\hline$t_{0.5}(h)$ & 7.61 & 7.69 & 0.897 \\
\hline
\end{tabular}

- Table 5 Saliva pharmacokinetic parameters of hydrochlorothiazide test and reference formulations.

\begin{tabular}{|l|r|r|l|}
\hline Parameter & \multicolumn{1}{|c|}{ Test } & Reference & P value \\
\hline $\mathbf{A U C}_{\mathbf{0} \rightarrow \mathbf{t}}(\mathbf{n g} / \mathbf{m l} \mathbf{~ h )}$ & 87.66 & 91.38 & 0.372 \\
\hline $\mathbf{A U C}_{\mathbf{0} \rightarrow \infty}(\mathbf{n g} / \mathbf{m l} \mathbf{h})$ & 116.57 & 111.95 & 0.646 \\
\hline $\mathbf{C}_{\max }(\mathbf{n g} / \mathbf{m l})$ & 15.65 & 18.12 & 0.548 \\
\hline $\boldsymbol{T}_{\max }(\mathbf{h})$ & 5.42 & 4.25 & $0.262^{*}$ \\
\hline $\mathbf{t}_{\mathbf{0 . 5}}(\mathbf{h})$ & 5.96 & 6.43 & 0.704 \\
\hline $\mathbf{K}_{\mathbf{e l}}(\mathbf{h}-\mathbf{1})$ & 0.15 & 0.19 & 0.681 \\
\hline \multicolumn{4}{|l}{$:$ Wilcoxon test was done for $\mathrm{T}_{\max }$} \\
\hline
\end{tabular}

- Table 6 Bioequivalence metrics: point estimate (90\%lower limit-90\%upper limit), intra-subject variability for hydrochlorothiazide in plasma and saliva after log transformation.

\begin{tabular}{|l|l|l|}
\hline $\begin{array}{l}\text { Param- } \\
\text { eter }\end{array}$ & Plasma & Saliva \\
\hline AUC $_{0 \rightarrow \mathrm{t}}$ & $103.1(94.7-112.3), 11.6$ & $93.9(82.8-106.5), 17.2$ \\
\hline AUC $_{0 \rightarrow \infty}$ & $102.4(94.6-110.9), 10.8$ & $103.8(90.4-119.3), 18.9$ \\
\hline $\mathbf{C}_{\max }$ & $114.8(94.4-139.7), 26.9$ & $91.9(71.188-118.801), 35.7$ \\
\hline
\end{tabular}

fall within the acceptance range of $80-125 \%$, except for $C_{\max }$ that could be due to the small sample size and this is reflected with the high intra-subject variability as shown in > Table 6 .

Higher variability in saliva is observed as compared with plasma, which can be due to inter-subject variability in drug protein binding and drug membrane permeability. Hence, more subjects are
- Table 7 ANOVA $P$ values of $\left(\mathrm{AUC}_{0 \rightarrow \mathrm{t}}, \mathrm{AUC}_{0 \rightarrow \infty}, \mathrm{C}_{\max }\right)$ for hydrochlorothiazide in plasma and saliva * .

\begin{tabular}{|l|c|c|}
\hline Source & Plasma & Saliva \\
\hline Sequence & $0.689,0.699,0.302$ & $0.464,0.472,0.342$ \\
\hline Subject (Sequence) & $0.011,0.006,0.277$ & $0.001,0.002,0.170$ \\
\hline Treatment & $0.531,0.598,0.231$ & $0.389,0.635,0.566$ \\
\hline Period & $0.207,0.070,0.163$ & $0.615,0.205,0.754$ \\
\hline \multicolumn{2}{|c|}{ * ANOVA analysis of variance; $\mathrm{AUC}_{0 \rightarrow 24}$ area under concentration } \\
curves to last collection time; $\mathrm{AUC}_{0 \rightarrow \infty}$ area under concentration \\
$\begin{array}{l}\text { curves to infinity; } \mathrm{C}_{\max } \text { maximum measured concentration. Level of } \\
\text { significance is 0.05 }\end{array}$ \\
\hline
\end{tabular}

- Table 8 Saliva to plasma ratios of test and reference formulations.

\begin{tabular}{|c|c|c|}
\hline Parameter & Test & Reference \\
\hline AUC $^{*}$ & 0.23 & 0.25 \\
\hline$C_{\max }{ }^{*}$ & 0.27 & 0.38 \\
\hline$T_{\max }{ }^{*}$ & 2.67 & 2.05 \\
\hline$C^{*}$ & 0.21 & 0.23 \\
\hline \multicolumn{3}{|c|}{ 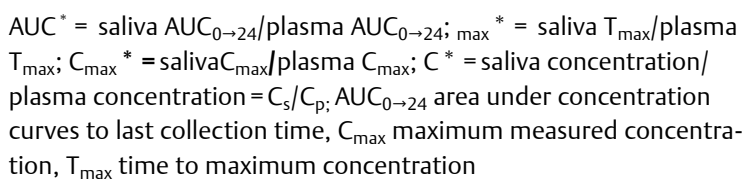 } \\
\hline
\end{tabular}

required in studies using saliva matrix compared with plasma matrix. ANOVA p values showed no significant differences in the pharmacokinetic parameters between test and reference in all sources except Subject (Sequence) in $\mathrm{AUC}_{0 \rightarrow 24}$ and $\mathrm{AUC}_{0 \rightarrow \infty}$ in both plasma and saliva as shown in $>$ Table 7.

From a regulatory point of view, , bioequivalence studies using saliva matrix is not against international guidelines. For example, the US FDA guidance for industry stated, "The statutory definitions of $B A$ and $B E$, expressed in terms of rate and extent of absorption of the active ingredient or moiety to the site of action, emphasize the use of pharmacokinetic measures in an accessible biological matrix such as blood, plasma, and/or serum to indicate release of the drug substance from the drug product into the systemic circulation" and "Biological matrix: A discrete material of biological origin that can be sampled and processed in a reproducible manner. Examples are blood, serum, plasma, urine, feces, saliva, sputum, and various discrete tissues." [http://www.fda.gov/cder/guidance/ index.htm]. Also, saliva matrix is mentioned clearly in the Japanese guidance [http://www.nihs.go.jp/drug/BEguide-E.html].

Dimensional analysis for the ratios of saliva to plasma is shown in $>$ Table 8. It showed low saliva/plasma ratiosin the AUC and $C_{\text {max }}$ with a longer $T_{\max }$. This could be due to the low permeability of hydrochlorothiazide that led to low saliva to plasma ratios. $\mathbf{F i g .} 4$ shows valsartan observed versus PK-Sim/Mobi predicted plasma concentration with good fitting line between observed and predicted. Optimized effective intestinal permeability estimated was equalto $5.00598 \times 10^{-5} \mathrm{~cm} / \mathrm{s}$. valsartan has low permeability despite the high partition coefficient $(\log P)$ that was correlated with permeability classification according to BCS (Biopharmaceutics Classification System) that classified drugs according to permeability and solubility [19]. It was found that valsartan is exposed to intestinal efflux transporter $\mathrm{p}$-glycoprotein that limits its transport 


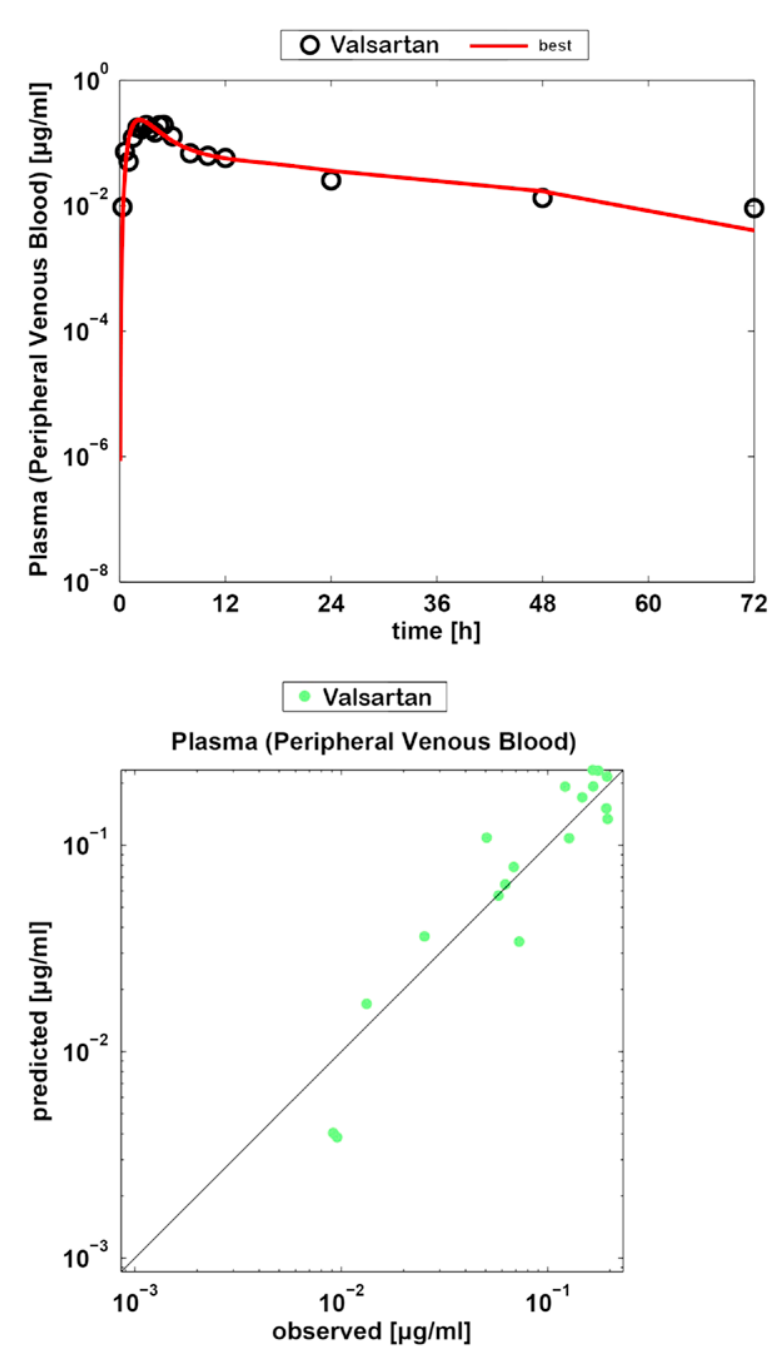

- Fig. 4 Observed versus PK-Sim/Mobi predicted valsartan plasma concentrations

from the intestinal lumen and lead to low intestinal permeability $[20,21]$. $>$ Fig. 5 shows hydrochlorothiazide observed versus PKSim/Mobi predicted plasma concentration with good fitting line between observed and predicted and the estimated optimized effective intestinal permeability was equal to $7.60281 \times 10^{-9} \mathrm{~cm} / \mathrm{s}$.

\section{Conclusion}

The data collected suggest that salivary hydrochlorothiazide can be used as alternative to plasma sample in pharmacokinetic studiesand in bioequivalence when adequate sample size is used.

\section{Acknowledgements}

This research was funded by University of Petra. We thank all medical staff at Red Crescent Hospital for their cooperation. PK-Sim program used under academic license from BAYER Technology Service, Germany.

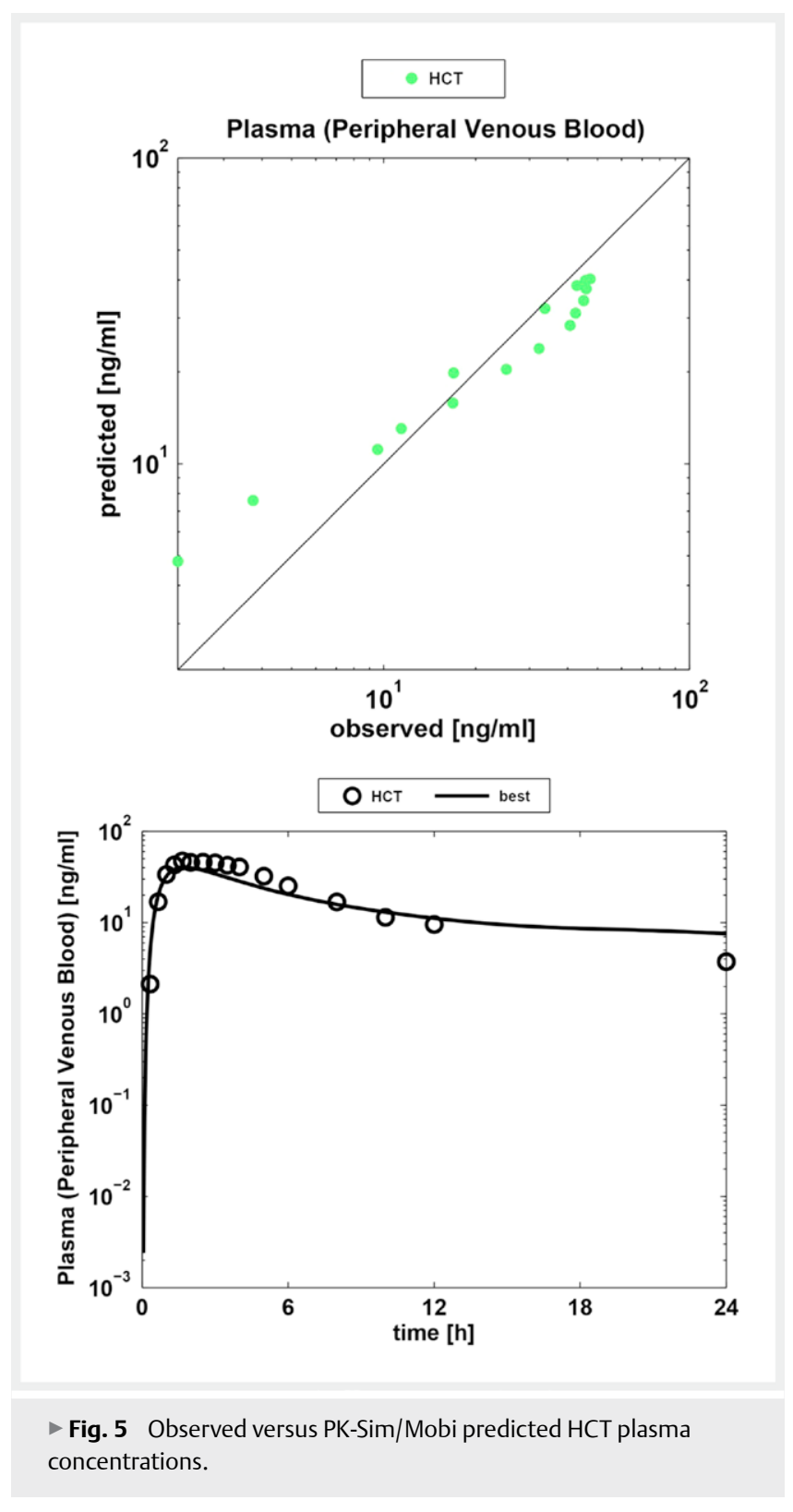

Conflict of interest

Authors declare no conflict of interest. This work was done in partial fulfillment of master of science in Pharmaceutics at Petra University.

\section{References}

[1] Idkaidek N, Arafat T. Saliva versus plasma pharmacokinetics: Theory and application of a salivary excretion classification system. Molecular pharmaceutics 2012; 9: 2358-2363

[2] Ashavaid T, Dheraj A. Therapeutic drug monitoring-A review. Indian Journal of Clinical Biochemistry 1999; 14: 91-94

[3] Danhof M, Breimer D. Therapeutic drug monitoring in saliva. Clinical pharmacokinetics 1978; 3: 39-57 
[4] Drobitch RK, Svensson CK. Therapeutic drug monitoring in saliva. Clinical pharmacokinetics 1992; 23: 365-379

[5] Liu H, Delgado MR. Therapeutic drug concentration monitoring using saliva samples. Clinical pharmacokinetics 1999; 36: 453-470

[6] Kaufman E, Lamster IB. The diagnostic applications of saliva-a review. Critical Reviews in Oral Biology \& Medicine 2002; 13: 197-212

[7] Mandel ID. The diagnostic uses of saliva. Journal of Oral Pathology \& Medicine 1990; 19: 119-125

[8] Elmongy H, Abdel-Rehim M. Saliva as an alternative specimen to plasma for drug bioanalysis: A review. TrAC Trends in Analytical Chemistry 2016; 83: 70-79

[9] Van Oosten M, Notten F, Mikx F. Metronidazole concentrations in human plasma, saliva, and gingival crevice fluid after a single dose. Journal of dental research 1986; 65: 1420-1423

[10] Matin SB, Wan SH, Karam JH. Pharmacokinetics of tolbutamide: prediction by concentration in saliva. Clinical Pharmacology \& Therapeutics 1974; 16: 1052-1058

[11] Kumar AH, Gurumurthy P. Ofloxacin pharmacokinetics in saliva. Indian journal of pharmacology 2004; 36: 80

[12] Criscione L, Gasparo M, Buhlmayer P et al. Pharmacological profile of valsartan: A potent, orally active, nonpeptide antagonist of the angiotensin II AT1-receptor subtype. British journal of pharmacology 1993; 110: 761-771

[13] Flesch G, Muller P, Lloyd P. Absolute bioavailability and pharmacokinetics of valsartan, an angiotensin II receptor antagonist, in man. European journal of clinical pharmacology 1997; 52: 115-120
[14] Wellington K, Faulds DM. Valsartan/hydrochlorothiazide. Drugs 2002; 62: 1983-2005

[15] Prasad PP, Yeh C-M, Gurrieri P et al. Pharmacokinetics of multiple doses of valsartan in patients with heart failure. Journal of cardiovascular pharmacology 2002; 40: 801-807

[16] Black HR, Bailey ], Zappe D et al. Valsartan. Drugs 2009; 69: 2393-2414

[17] Sica DA, Carter B, Cushman W et al. Thiazide and loop diuretics. The journal of clinical hypertension 2011; 13: 639-643

[18] Brunton LL, Chabner BA, Knollmann BC. Goodman \& Gilman's The pharmacological basis of therapeutics.2011:New York: McGraw-Hill Medical; pp 689-690 769-770, 736

[19] Dahan A, Miller JM, Amidon GL. Prediction of solubility and permeability class membership: provisional BCS classification of the world's top oral drugs. The AAPS journal 2009; 11: 740-746

[20] Challa VR, Ravindra Babu P, Challa SR et al. Pharmacokinetic interaction study between quercetin and valsartan in rats and in vitro models. Drug development and industrial pharmacy 2013; 39: 865-872

[21] Lozoya-Agullo I, González-Álvarez I, González-Álvarez M et al In Situ Perfusion Model in Rat Colon for Drug Absorption Studies: Comparison with Small Intestine and Caco-2 Cell Model. Journal of pharmaceutical sciences 2015; 104: 3136-3145 